\title{
A strategy for on-machine springback measurement in rotary draw bending using digital image-based laser tracking
}

\author{
Taekwang Ha ${ }^{1,2}$ - Torgeir Welo ${ }^{1}$. Geir Ringen ${ }^{1}$. Jyhwen Wang ${ }^{3} \mathbb{C}$
}

Received: 1 July 2021 / Accepted: 4 October 2021 / Published online: 7 November 2021

(C) The Author(s) 2021, corrected publication 2022

\begin{abstract}
Rotary draw bending is a commonly used metal forming technique for profile bending. Due to the elastic recovery of the material, springback compensation to control the bent product quality is one of the critical manufacturing issues. The realized bend angle has to be measured for springback compensation before removing the profile from the machine, and the bending process can follow an iterative approach until the product quality is satisfied. However, this trial-and-error is costly for batch production in manufacturing. An on-machine measurement technique is therefore developed to measure springback in rotary draw bending with an affordable laser and a webcam. An image processing technology is integrated with the manufacturing process to track the deformation and measure springback angle in real time, eliminating the need for the workpiece to be transferred to a measurement device. In this paper, bending experiments were conducted with AA6082 rectangular hollow profiles bent at $30^{\circ}, 45^{\circ}, 60^{\circ}$, and $90^{\circ}$ angles, and springback angles from the conventional manual measurement were compared to that from the on-machine measurement. Since the difference in springback measurement between the proposed and the conventional methods was within $0.15^{\circ}$ on average, it is demonstrated that the laser tracking, on-machine measurement is a feasible real-time springback measurement technique for Industry 4.0.
\end{abstract}

Keywords On-machine measurement $\cdot$ Tube bending $\cdot$ Springback $\cdot$ Laser tracking

\section{Introduction}

The constant striving for cost reduction, quality improvement, and lightweighting of products is a significant challenge to many manufacturing industries. This leads to the preference for relatively lightweight materials, but controlling springback after forming presents a challenge for processing-sensitive lightweight alloys. As a countermeasure, springback, due to elastic recovery after unloading in a metal forming process, is controlled by a feedback control

Jyhwen Wang

jwang@tamu.edu

1 Department of Mechanical and Industrial Engineering, Norwegian University of Science and Technology,

Trondheim, Norway

2 Department of Multidisciplinary Engineering, Texas A\&M University, College Station, TX, USA

3 Department of Engineering Technology and Industrial Distribution, Texas A\&M University, College Station, TX, USA algorithm to satisfy the required final geometric dimensions [1]. Welo and Granly [2] used an analytical model for feedback control of a rotary compression bending. The closedloop model was operated in real time, and the torque and the rotation angle were measured in the process for feedback control. Löbbe et al. [3] controlled springback in progressive bending with induction heating. The induction heating was controlled by a feedback algorithm through measured a springback angle. According to Pan and Stelson [4], the optimal process for springback compensation is traditionally achieved by the less scientific approaches, i.e., operator's experience, skill, or trial-and-error. Multiple bend trials are essential, which finds a better bending process. Borchmann et al. [5] demonstrated that by conducting a sensitivity analysis of practical bending tests and developing a digital equipping support database, the product quality could be made user-independent. Since springback control or compensation begins with knowing the status of the product's geometry regardless of automatic control or manual control, the first step to control the product quality is to acquire an accurate dimensional change due to springback. 
Geometric measurement is fundamental to assess product dimensions, monitor manufacturing processes, and improve product quality. To monitor and evaluate springback in a bending process, different types of measuring techniques have been developed based on contact or non-contact methods. Since a bevel protractor is simple and relatively less time-consuming to measure an inner or outer angle, it is often used to measure springback angles: springback relationships between parameters influencing springback [6], validation of a feedback system for springback compensation in air bending [7], springback evaluation of sheet metals in vee bending using a neural network [8], and so on. While a bevel protractor can be a good approach to measure an angle between flat surfaces, in the case of a tube or a rounded product, it is sometimes challenging to align the tangential surfaces with a protractor. A coordinate measurement machine (CMM) is also commonly used to accurately measure geometry dimensions by physically touching measuring points, but being less efficient to acquire the data on the grounds that the bent samples are transferred to a CMM and collecting many sampling data takes much of measuring time. Wang et al. [7] adopted linear variable differential transformers (LVDT) to calculate bending angles of loading and unloading cycles in air bending. The measured values were used for feedback control in incremental air bending. Ghiotti et al. [9] presented an in-line measurement method for real-time springback measurement by embedding an inertia measurement unit (IMU) into a mandrel in threeroll bending. The IMU attached to the mandrel allows the springback to be measured in a single process, but the use of the springback measurement method presumes the existence of a mandrel. A closed-loop controlled profile bending platform developed by Welo and Granly [2] recorded in process torque and rotation to indirectly measure springback. The closed-loop feedback control showed three times more process capability of dimension than traditional processes. Although the parameters such as torque and rotation are measured in the process, the accuracy of the springback measurement depends on the accurate prediction model to calculate springback using a steering model with directly measured parameters as input.

With the latest advancement in image processing or computer vision technology, new approaches integrating optical technologies for springback measurement have been applied to metal forming. Wang et al. [10] compared the geometry model to a rebuilt configuration of an automotive panel by scanning point data on the panel surface. The obtained data were used to update the die for springback compensation. Katona et al. [11] integrated three-dimensional optical measurement to inspect a bent pipe in a pipe bending process, as an alternative to a conventional inspection gauge. An optic-aided measurement helps save processing time for quality control, as well as evaluate the product status without removing the workpiece in the process. A laser is frequently used as a reference to mark targets for measuring distance or position in real time [12] due to its outstanding characteristic of the so-called laser directionality, which is a non-contact measurement technique applicable to springback measurement. Ha et al. [13] measured springback angle on the tube bending process by installing a laser fitment at the tip of a circular tube and capturing the laser moving distance on the target board. One of the limitations of the measurement method is that the laser moving distance needs to be manually read, and this is time-consuming and causes time delay when evaluating springback angle. Löbbe et al. [3] employed two parallel laser sensors to measure springback angle at different temperatures of progressive die bending. The laser sensors installed in the die gauged the distance to the workpiece, and the bent angle was calculated with the triangulation principle. The measurement technique demonstrated a capability of $\pm 0.25^{\circ}$ measurement error. The applicability of laser sensors relies upon sufficient space to install them on a die, though.

Many springback measurement techniques have strong capabilities in obtaining accurate measurement data. Sensorbased in-line measurement, however, can facilitate the adoption of Industry 4.0. In-line measurement techniques allow real-time monitoring of manufacturing processes. By identifying the current status of tube bending, for example, the monitoring system can be connected to a control system to adjust the process parameters to meet product quality requirement. To replace an off-line quality control and expensive inspection procedures, this paper addresses an easily manageable, simple, and cost-effective on-machine measurement technique to monitor springback in rotary draw bending (RDB) in real time, by integrating image processing based laser beam tracking. It allows springback angle in RDB to be conveniently measured by an affordable sensing system.

The goal of this research is to develop a new strategy for on-machine springback measurement focused on RDB. The measurement strategy and the laser tracking technique using digital images are addressed in Sect. 2. In the present study, a 635-nm laser installed at the tip of a profile was tracked to observe the profile's elastic behavior in different bending cases. An image processing technology using a MAT$\mathrm{LAB}$ platform was integrated for data acquisition during the bending process in real time. Presented in Sect. 3, image enhancement techniques [14], i.e., image quantization, binarization, and segmentation, were applied to make input images suitable for laser beam tracking. Section 4 shows the on-machine measurement experiments and the comparison between the measurements from the proposed method and the conventional manual method. Conclusions of the present research are presented in Sect. 5. 


\section{Proposed springback measurement concept}

Previously, Ha et al. [13] suggested an in-line springback measurement method by installing a laser fitment at the tip of a profile and manually reading the laser travel distance on a graph paper attached to a datum board, as shown in Fig. 1. The geometric deformation of a profile is shown as a laser moving on the target. Although the method is appropriate to measure in-line springback angle, it takes time to manually read the laser moving distance based on the grid size. Figure 1 illustrates an experimental system for in-line springback measurement and the laser beam spot of loading and unloading on the datum board.

Ferreira et al. [15] developed a springback evaluation technique for stamping with image processing. The filtered workpiece image was used to evaluate springback angle. In this research, instead of detecting the workpiece shape, the digital image-based laser tracking was integrated into the laser measurement method to measure springback angle for on-machine measurement in real time, as shown in Fig. 2. An affordable webcam connected to a computer was used for image acquisition, and the acquired images with 30 frames per second (fps) were analyzed to calculate springback angle in real time; every single image frame has a single laser beam spot being projected on the datum board. The beam spot reflects the geometric change of the sample as a reference in the machine.
A laser fitment is made up of a Class 2 laser and an adaptor to hold the laser, which is installed into the aluminum profile before the bending process. The wavelength of the laser used is red-colored $635 \mathrm{~nm}$ and the power is 1 $\mathrm{mW}$. This laser is the same as that in a laser pointer and is safe for industrial operation when laser safety guidelines are followed. The device for image acquisition can be positioned in various ways. However, it was set in front of a datum board to avoid perspective images for less image processing and directly linked to a computer for image acquisition, processing, and springback calculation in real time.

Figure 3 shows a schematic image with $640 \times 480$ resolution, which is displayed on a computer monitor. The laser beam spot on the image was captured with a rectangular bounding box and a crosshair. The bounding box indicates the location of the laser beam, and the crosshair describes the centroid of the laser beam. The centroid as a beam location was used for tracking a laser beam. Only one laser beam, detected by image processing, is shown in the actual image. The beam moves from right to left on the datum board in Fig. 3, as the tube springs back after unloading. The location of the captured laser beam upon final loading and after unloading, respectively, is tracked, and the moving distance is used to calculate the springback angle. The 50-mm-long reference line on the datum board (see Fig. 3) is used for converting from the laser beam traveling on the computer monitor to the actual distance on the datum board. In other words, calculating the distance per pixel enables the tracking of laser beam motion on the datum board.
Fig. 1 Schematic of in-line springback measurement

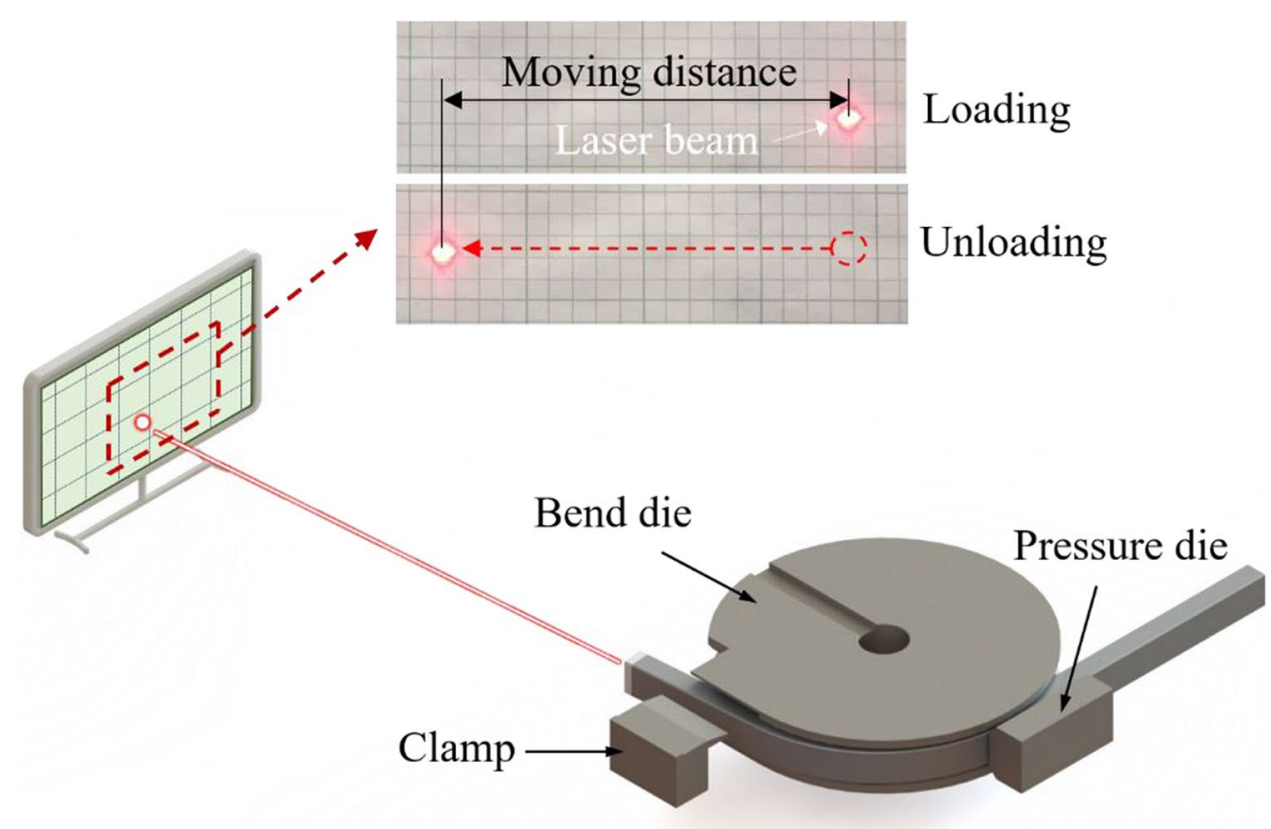


Fig. 2 Schematic of real-time springback measurement, a loading; b unloading

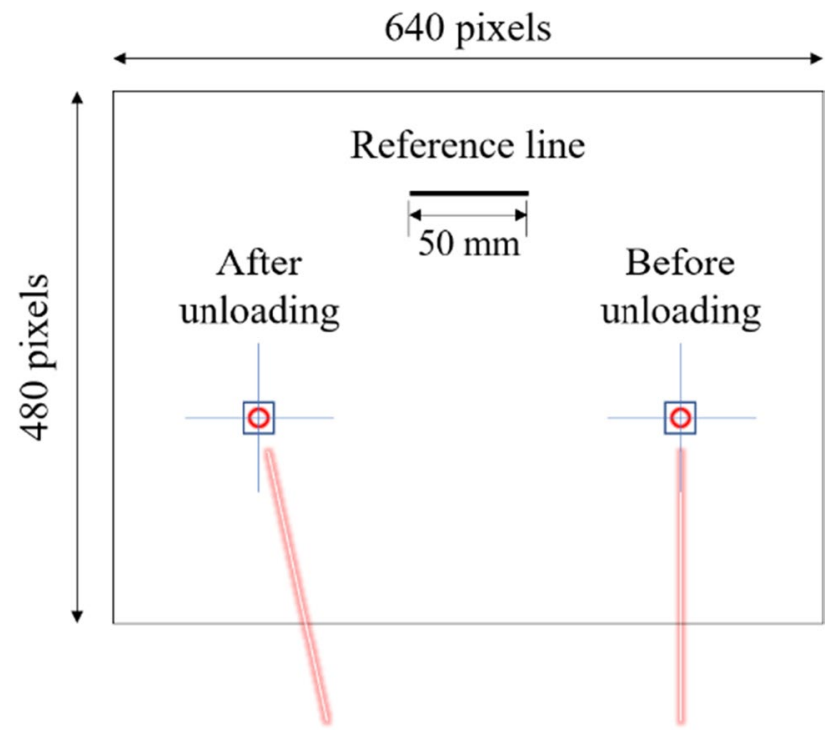

Fig. 3 Schematic of a laser tracking image a Datum(Target) board

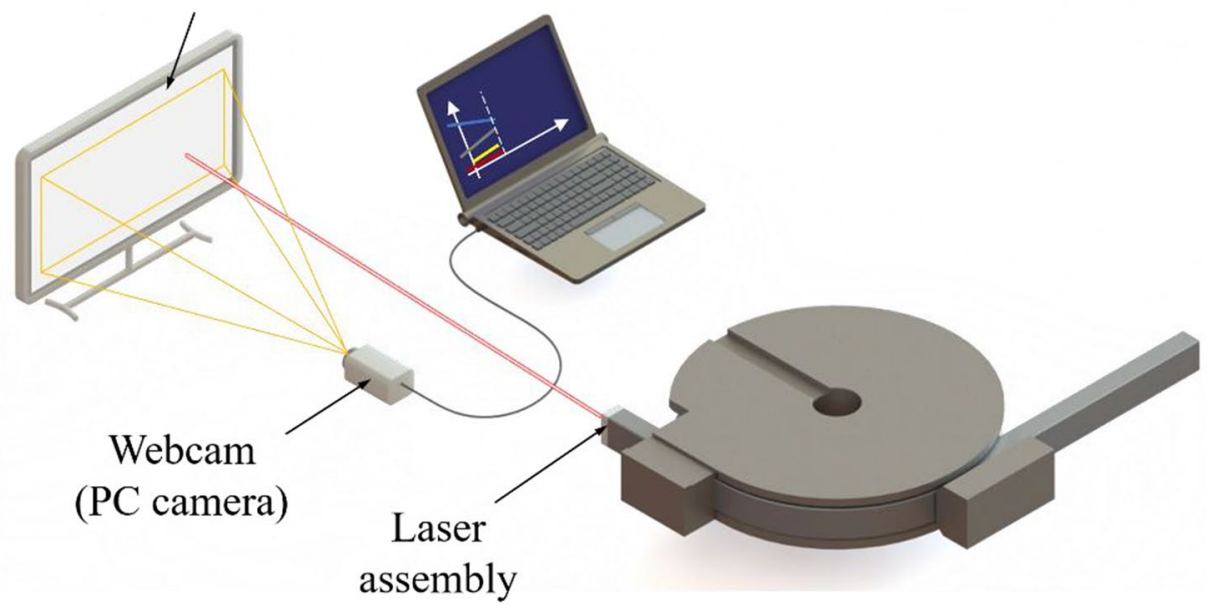

b

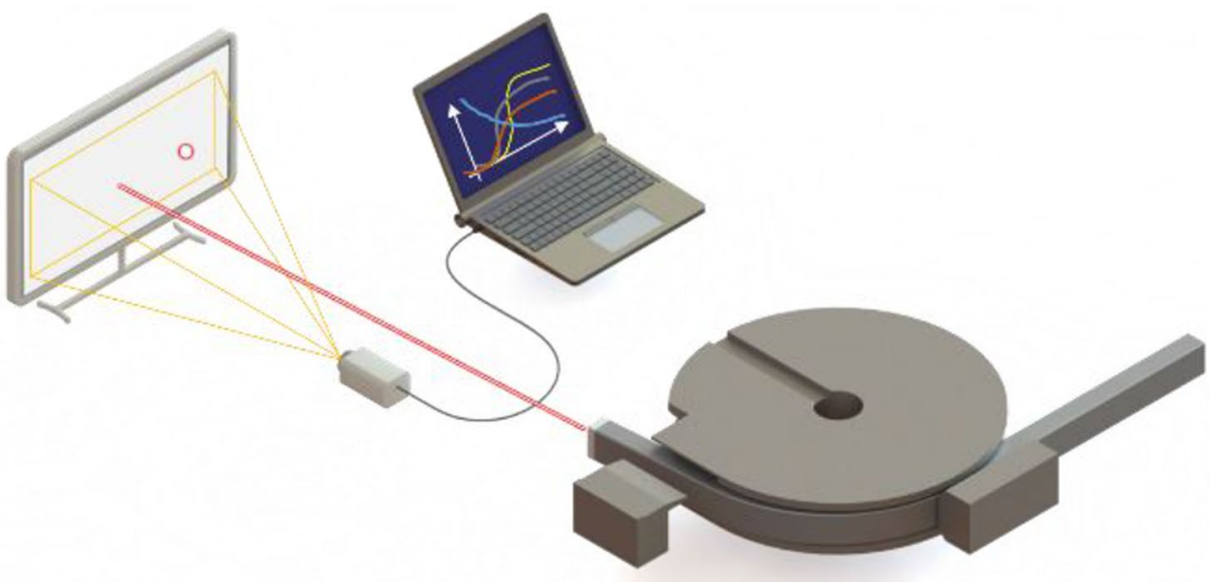

\section{Springback measurement approach in the rotary draw bending process}

\subsection{Digital image processing for laser beam tracking}

A color image has three-dimensional color information being allocated to each pixel of the image. For a singlechannel image processing, the three-color components are quantized to the gray scale which only has a light intensity with an 8-bit depth. Image quantization is a process for dimensional reduction to gray scale; thus, it allows each pixel to get a single light intensity and one-dimensional information. Converting color to gray scale is also referred to as image decolorization.

The luminance method [16] or weighted method considering the brightness perception of human eye is one of the converting algorithm, which is widely used for converting a color image into a gray scale image. Luminance by Recommendation ITU-R BT.601-7 is the combination of 
red, green, and blue (RGB) channels with each weighting as follows:

$I=0.299 R+0.587 G+0.114 B$

Each pixel of a color image is composed of RGB channels; however, the gray scale luminance of the $i$ th frame by Eq. (1) can be represented by

$I_{i}(x, y)=\left[\begin{array}{ccc}I(0,0) & \cdots & I(0, n-1) \\ \vdots & \ddots & \vdots \\ I(m-1,0) & \cdots & I(m-1, n-1)\end{array}\right]$

where $I$ is pixel intensity, $i$ is the number of image frames, $x$ and $y$ are spatial coordinates, and $m$ and $n$ represent pixels of an image resolution.

As mentioned, a reference line was marked on the datum board to calculate the distance per pixel. The filtered gray scale image of a datum board with a reference line was segmented with the global thresholding technique [17] for background subtraction [18, 19]. Figure 4 shows the image histogram of Fig. 5a and the threshold is indicated for image filtering. The segmented image, $G(x, y)$, by thresholding is expressed as follows:

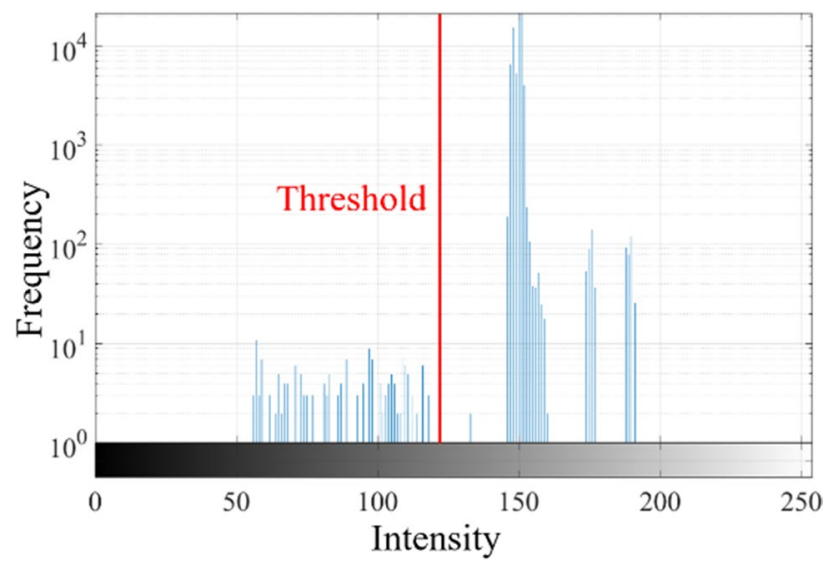

Fig. 4 Image histogram of the gray scale image
$G(x, y)=\left\{\begin{array}{c}1 \text { if } \mathrm{I}(x, y)>\text { Threshold } \\ 0 \text { otherwise }\end{array}\right.$

While image thresholding with a fixed level is not suitable to divide the interested region from the image background [20], a fixed-level threshold in Fig. 5 was used for image segmentation due to the simple background of the datum board. Based on the image histogram of Fig. 4, a gray scale image and a segmented image after thresholding are shown in Fig. 5.

To remove unnecessary noise for object detection, the region of interest (ROI) for the reference line shown in Fig. 6a was extracted from the image background. The extracted ROI was converted to gray scale using Eq. (1). Figure 6 presents the ROI of the original image and the reference line surrounded by a bounding box. The number of pixels in the reference line was calculated by the diagonal length of the bounding box. Instead of longitudinal length in the bounding box, the diagonal length was used to reduce errors from a skewed image. The actual laser moving distance on the datum board can be computed based on the distance per pixel of the prescribed reference line on the computer monitor.

In the same manner as the above technique, the image frame for the laser beam was also converted to the gray scale and binary image. The segmented binary image has a background with 0 and a laser beam with 1 . The target object is recognized by the binary information, and the object is being tracked. The goal of object tracking is to obtain its trajectory of every input frame by image processing [21]. A target object of an image frame can be represented by a centroid for object tracking. The centroid of the laser beam intensity was computed based on the binarized image. The centroid of a spatial coordinate, $C(\bar{x}, \bar{y})$, is given by

$\bar{x}=\frac{\sum_{x} \sum_{y} x \cdot I(x, y)}{\sum_{x} \sum_{y} I(x, y)}, \bar{y}=\frac{\sum_{x} \sum_{y} y \cdot I(x, y)}{\sum_{x} \sum_{y} I(x, y)}$

The laser beam movement on the datum board upon springback is found by the difference in the centroid position after springback compared to the initial position of the centroid. The laser moving distance per frame can be evaluated
Fig. 5 Image thresholding, a gray scale; $\mathbf{b}$ segmented image a

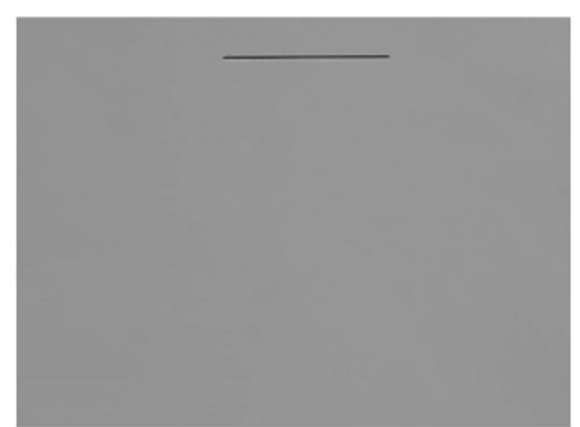

b

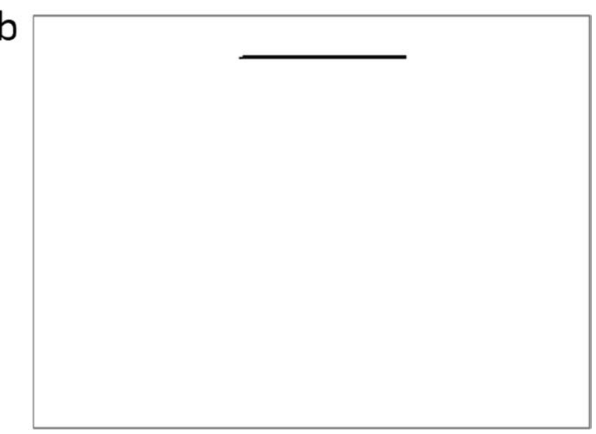


Fig. 6 a ROI of the original image; $\mathbf{b}$ bounding box of the ref. line a

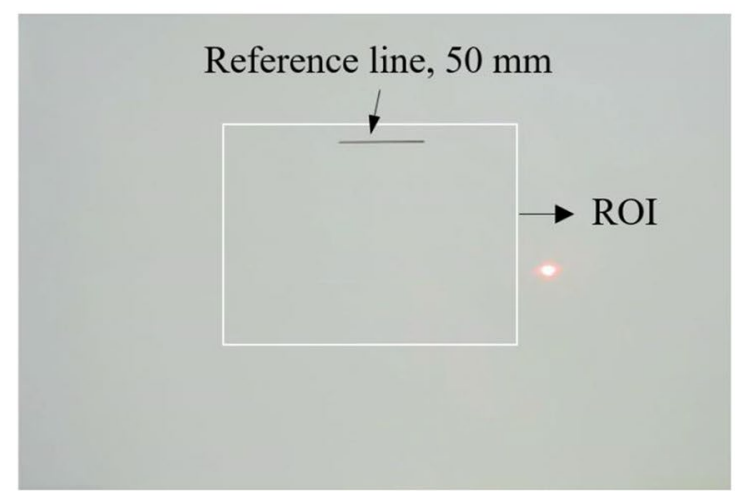

b

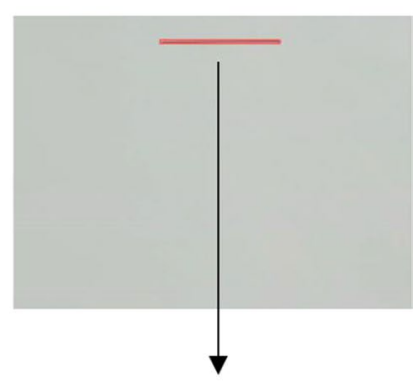

Bounding box by the Euclidean distance of the centroid between the $i$ th and $(i+1)$ th frames. Therefore, the laser moving distance, $d$, in real time is computed by

$d=\sum\left\|C(\bar{x}, \bar{y})_{i+1}-C(\bar{x}, \bar{y})_{i}\right\|$

The image processing for laser detection and tracking is shown in Fig. 7. Here, Fig. 7a is the input frame, Fig. 7b is the image converted to an 8-bit gray scale, Fig. 7c is the binary image to identify an object, and Fig. $7 \mathrm{~d}$ is the output frame through image segmentation and filtering. The fully converted image, Fig. 7d, is used to display the laser beam position and to acquire the desired data. As mentioned above, the centroid which is an intersection of the crosshair in Fig. $7 d$ is tracked, and the centroid position is logged in real time.

In the algorithm for real-time springback measurement, there are two different image processing groups to calculate the laser beam position, as shown in Fig. 8. The first group is for the reference line, and the second group is for the laser beam tracking. Since the position of the image acquisition device, a webcam of Fig. 2, was not fixed, computing the distance per pixel of the reference line prior to laser beam tracking was required during setup. While image processing for the reference line is run once, image processing for laser beam tracking iterates until the end of image acquisition. The laser beam tracking can be performed by synthesizing two image processing algorithms.

\subsection{Geometric calculation of springback}

The springback angle, $\theta$, in Fig. 9 is taken as the difference between bending angle before unloading $\theta_{1}$ and released bending angle $\theta_{2} . \overline{A^{\prime} B}$ is the datum board distance from the neutral axis of the unbent tube, $\overline{A C}$ is the imaginary line of the profile's neutral axis after unloading, and $\overline{B C}$ is
Fig. 7 a Original image; $\mathbf{b}$ gray scale; c binary; $\mathbf{d}$ laser beam detection a

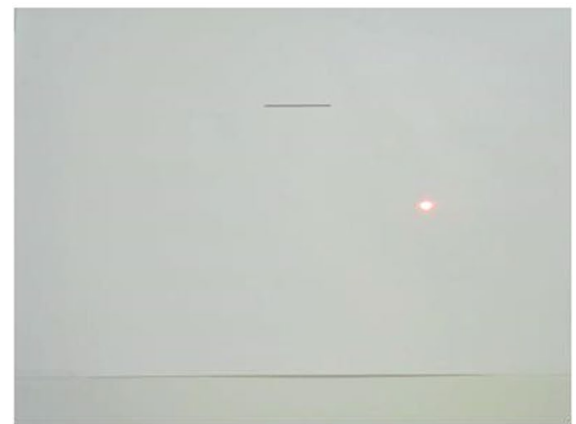

C



b

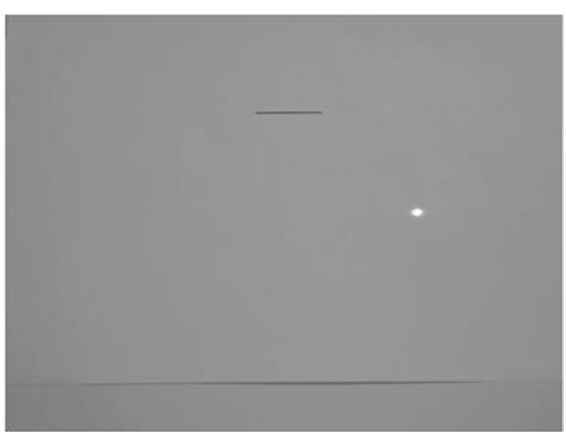

d

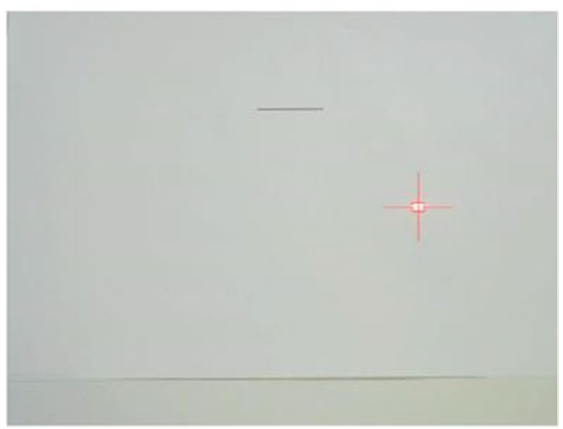




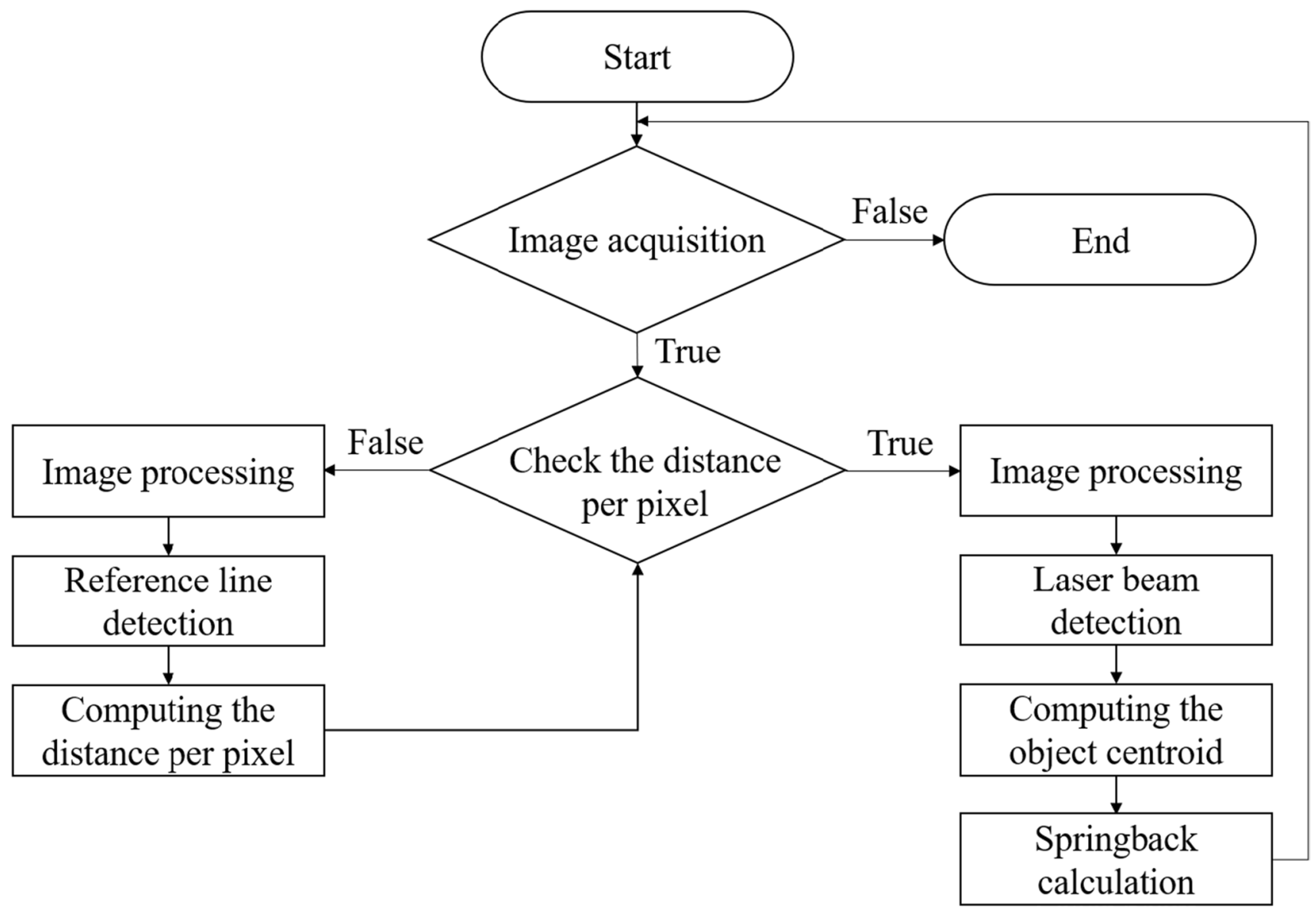

Fig. 8 Image processing flow for laser beam tracking

the actual moving distance of the laser beam on the datum board. The springback angle $\angle C A B$ can be calculated by trigonometry, which is given by

$\theta=\arctan \left(\frac{\overline{B C}}{\overline{A B}}\right)$ or $\theta=\arctan \left(\frac{\overline{B C^{\prime}}}{\overline{A^{\prime} B}}\right)$

Geometrically, the location of point $\mathrm{A}$ is unknown due to the unknown released bend angle, $\theta_{2}$. To overcome uncertainty and reduce the calculation error, $\mathrm{Ha}$ et al. [13] computed the springback angle by creating an imaginary line $\overline{A^{\prime} C^{\prime}}$ parallel to $\overline{A C}$ and updating a calibration distance $\overline{C C^{\prime}}$ based on an initial bent angle $\angle C A^{\prime} B . \overline{A^{\prime} C}$ moves towards $\overline{A^{\prime} C^{\prime}}$ by updating the calibration distance as follows

$\overline{C C^{\prime}}=\frac{\sin \left(\theta_{1}(1-\eta)\right)}{\cos \left(\theta_{1} \eta\right)}\left[\frac{r\left(\sec \theta_{1}-1\right)}{\tan \theta_{1}}-\frac{r\left\{\sec \left(\theta_{1}(1-\eta)\right)-1\right\}}{(1-\eta) \tan \left(\theta_{1}(1-\eta)\right)}\right]$

where $r$ is bending radius, $\theta_{1}$ is bend angle, and $\eta$ is springback ratio given by $\eta=\frac{\theta}{\theta_{1}}$

In this paper, the calibration distance is assumed sufficiently small, compared to the laser moving distance, $\overline{B C}$, to be neglected in the springback calculation. Then, the springback angle is approximated by

$\theta=\arctan \left(\frac{\sum\left\|C(\bar{x}, \bar{y})_{i+1}-C(\bar{x}, \bar{y})_{i}\right\|}{\overline{A^{\prime} B}}\right)$

\section{Experiment and discussions}

\subsection{Experimental setup}

The material used for RDB was the AA6082-T4 hollow rectangular tube with exterior dimensions $60 \times 40 \mathrm{~mm}$ and a thickness of $3 \mathrm{~mm}$. The bend die radius was $252 \mathrm{~mm}$, and 


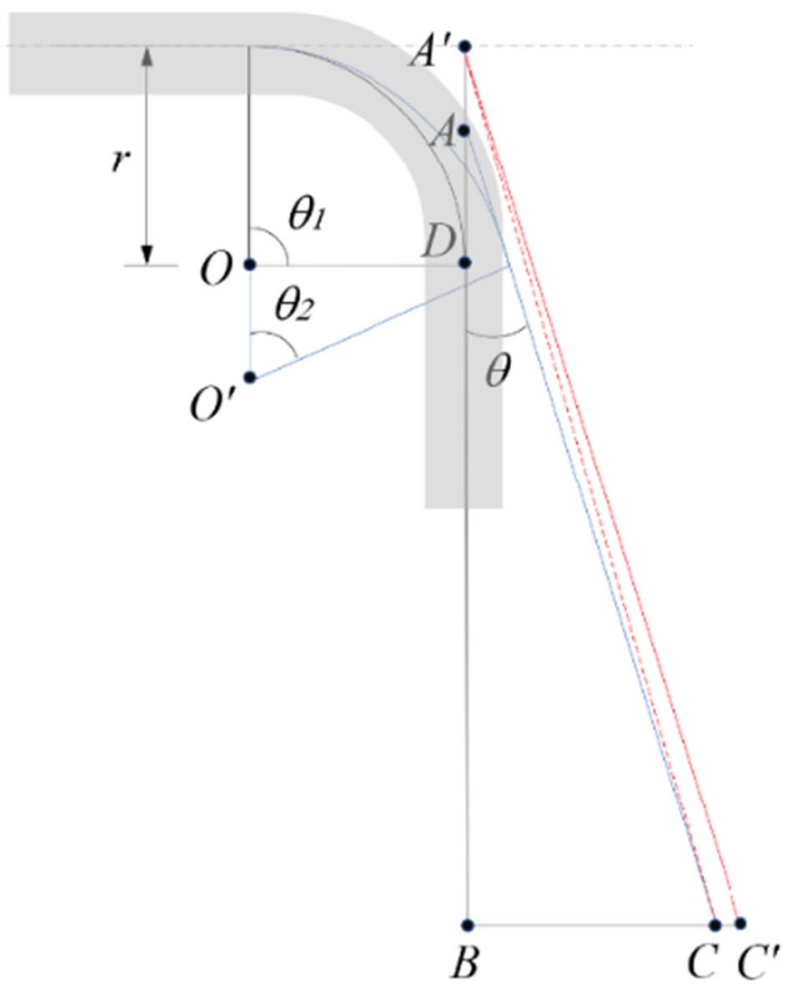

Fig. 9 Springback geometry of profile bending

the bending angles were $30^{\circ}, 45^{\circ}, 60^{\circ}$, and $90^{\circ}$. Three workpieces (950 $\mathrm{mm}$ long) were used for each bending angle. The datum board was installed at a $3.0-\mathrm{m}$ distance from the point $O$ in Fig. 9, the center of the bending radius.

A laptop computer with i5-7200U $2.5 \mathrm{GHz}$ and $8 \mathrm{~GB}$ memory was employed to realize a tracking system. A webcam with $720 \mathrm{p}(1280 \times 720)$ and $30 \mathrm{fps}$ connected to the computer acquired images during the unloading process. The image processing was performed in MATLAB. For each bending process, 90 frames with $640 \times 480$ true color $(24$ bits) images were obtained at a rate of about $10 \mathrm{fps}$ and were used to track the laser beam of the datum board in real time.

Figure 10a illustrates the overall experimental system viewed from the tube. The enlarged image displays the reference line and the laser beam on the datum board. A laser fitment was installed at the tip of the hollow profile shown in Fig. 10b. The laser beam was used for the indicator of the profile's longitudinal direction on the datum board. As noted above, the laser beam on the datum board was tracked by the image processing algorithm. The springback angle, $\theta$, in Fig. 10b was manually measured without taking the workpiece from the machine to compare the springback to on-machine measurement. Since RDB was conducted without mandrel and wiper die in the experiments, it was assumed that springback only occurs in the bent part, which eliminates any effect of the absence of wiper die and mandrel after unloading.

Springback can be calculated with a robust prediction model. However, springback is affected by complex process conditions such as material properties, geometry, lubrication, bending speed, and tooling, geometry. Since precise springback prediction is not an easy task, springback measurement is of great importance to control product quality and compensate springback.

Two different measurement methods were adopted for the springback measurement. Firstly, manual measurement of springback was carried out without removing the workpiece from the bending machine to verify the on-machine springback measurement in real time. The tube shapes at $30^{\circ}, 45^{\circ}$, $60^{\circ}$, and $90^{\circ}$ bending angles are shown in Fig. 11.

Secondly, the springback angle was monitored and measured in real time during the unloading process. This onmachine measurement method serves the purpose of measuring the springback angle by digital image-based laser
Fig. 10 Experimental setup, a view from a tube; $\mathbf{b}$ bent tube
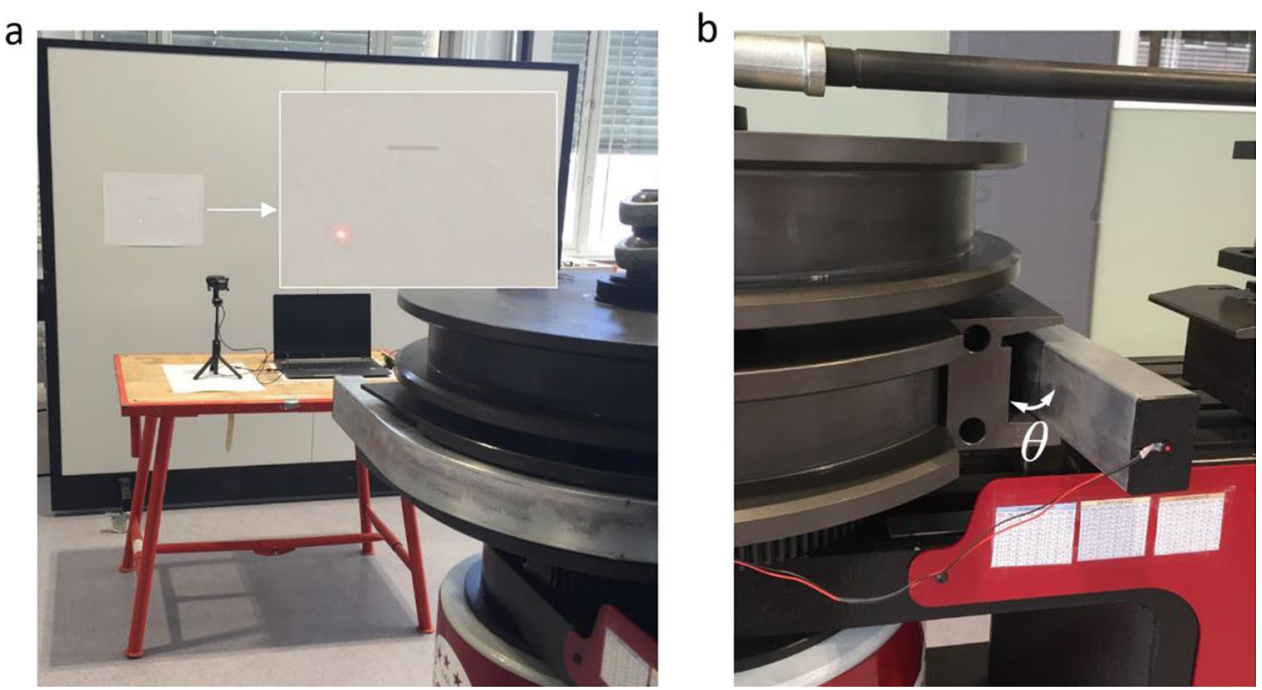
Fig. 11 Experimental workpieces, a $30^{\circ} ; \mathbf{b} 45^{\circ} ; \mathbf{c} 60^{\circ}$; d $90^{\circ}$ bending a

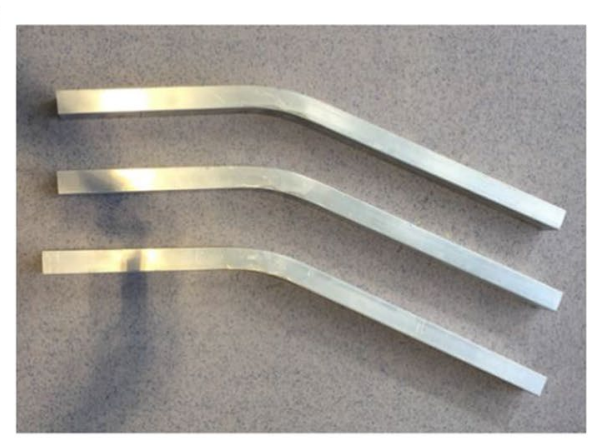

C

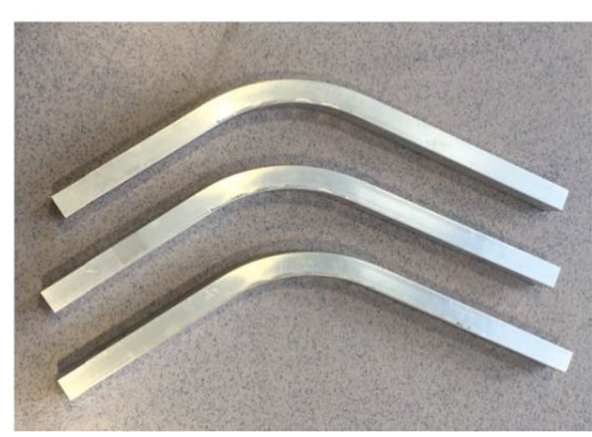

b

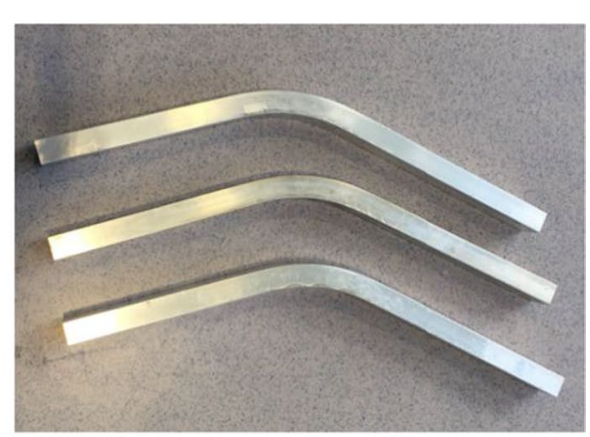

d

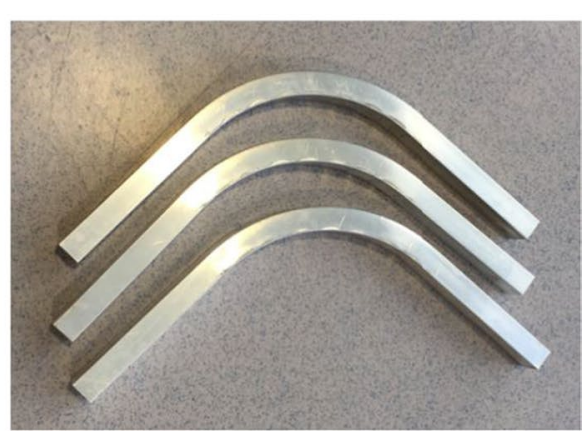

tracking, without transferring the workpiece for springback measurement. The image processing algorithm was run after each bending process, before the clamp was released and unloading performed.

The on-machine measurement results of springback are plotted in Fig. 12. Each graph has real-time springback data of three workpieces. The $\mathrm{x}$-axis indicates the frame number, and the $y$-axis indicates the springback angle. The webcam had a $30-\mathrm{Hz}$ frame rate. Due to the time spent on image processing, the output frame rate after the image process became $10 \mathrm{~Hz}$. The gray-colored circle in Fig. 12 is the starting point of unloading, as the clamp after bending was randomly released. Each profile was fully recovered in two or three frames after unloading, and the springback angle was rapidly increased and converged after unloading. The slope of springback also increased, as the bending angle increased. However, the sharp edges after unloading were shown in the $30^{\circ}$ bend angle in Fig. 12a because the clamp bumped against a stopper when it was fully released. The peak point was stabilized and converged fast. Accordingly, the effect of the clamp releasing vibration is considered negligible. The on-machine measurement graphs display that the image tracking algorithm follows the laser beam in real time, and tubes are less bent than the desired bending angle due to elastic recovery.

As an example of the image processing for on-machine springback measurement, the original and tracking images for $90^{\circ}$ bending are shown in Fig. 13. The images in Fig. 13a are the raw images from the image acquisition device, and Fig. 13b shows the object-captured images by object tracking in real time. The laser beam was located on the right side of the datum board as the initial position before unloading in the 1st frame. Unloading started at the 44th frame, and the laser beam moved from the 45th to the 48th frame. The final position of the laser beam is shown in the 90th frame. While the springback angle was calculated with the final laser position of the 90th frame based on the 90 input images, the real-time monitoring can also apply to determine the status of loading and unloading for on-machine springback measurement.

\subsection{Measurement results}

According to the image processing flow presented in Sect. 3, the springback was logged on the computer during the unloading process, and the springback was also manually measured after springback. The springback angles by onmachine measurements are listed with the manual measurement results in Table 1. Both measurements show that the springback increases with an increasing bend angle from $30^{\circ}$ to $90^{\circ}$. However, the standard deviation (SD) of the manual measurement is mostly higher than the image processing results. The average SD of the manual and on-machine measurements is $0.12^{\circ}$ and $0.09^{\circ}$, respectively.

The springback results are plotted with bar charts in Fig. 14. A line with two filled circles at its end is the relative difference slope between two different measurements based on the same workpiece. The maximum observed difference is $0.20^{\circ}$ of workpiece 2 in $30^{\circ}$ bending, and the minimum is $0.06^{\circ}$ of workpiece 3 in $30^{\circ}$ bending. For 
Fig. 12 On-machine springback measurement in real time

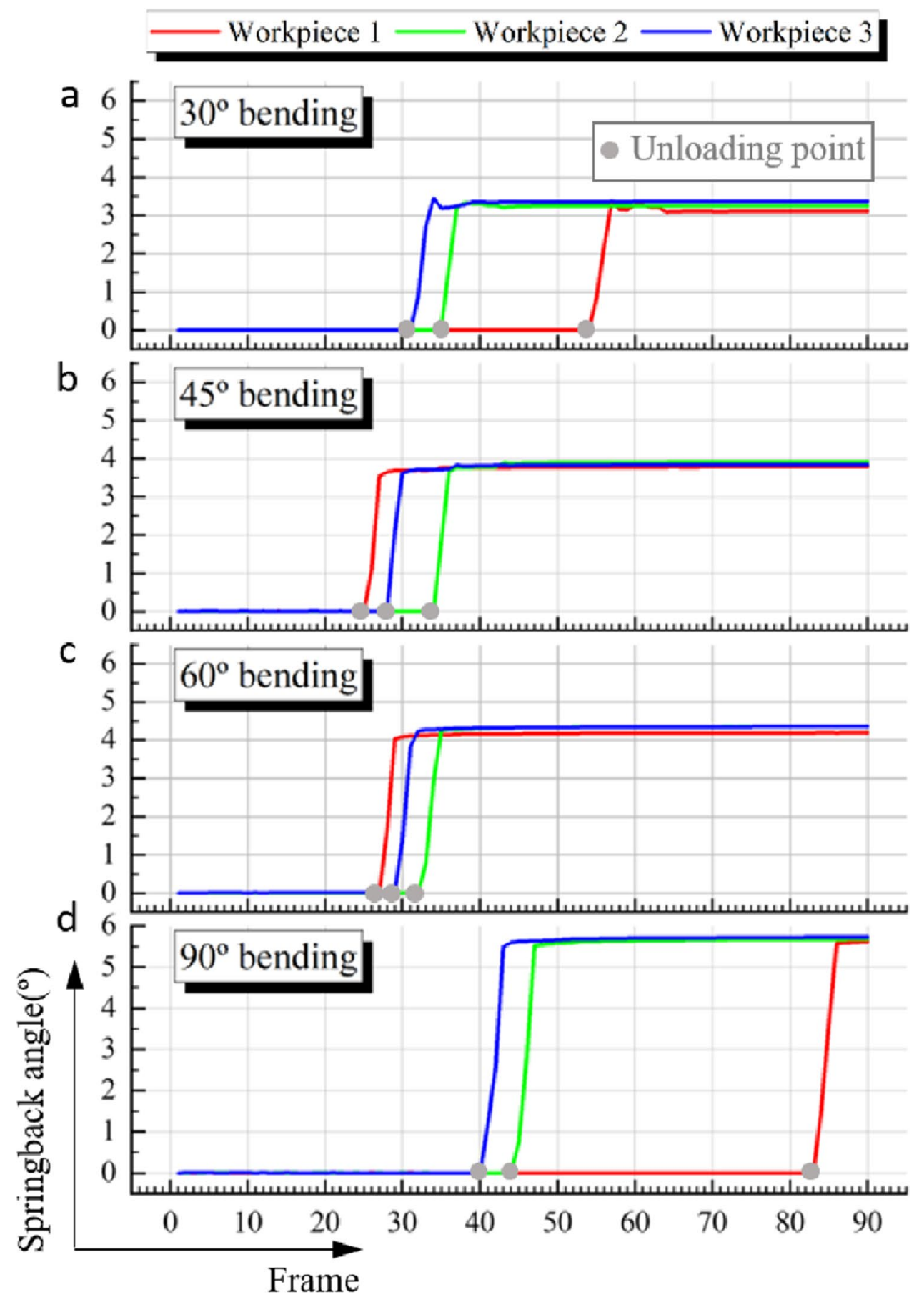

workpiece 1 bent at $90^{\circ}$, while the clamp was released at the 83rd frame as shown in Fig. 12 and the data logging was finished at 90th frame, the springback from the on-machine measurement was $0.11^{\circ}$ slightly higher than the manual measurement. It is considered that the unloading point does not critically affect the springback measurement. The springback difference of each workpiece had no particular trend, but the overall differences between manual and on-machine measurements were within $+0.20^{\circ} /-0.12^{\circ}$.
The averages of the springback angles and the differences between the two measurement techniques are plotted in Fig. 15. From the error bars in Fig. 15a, it can be observed that the variation of the measured springback angles, manual or on-machine, is very small. The springback values, as expected, increased as the bending angles increased due to the elastic recovery of the material. Since the differences between the averaged manual and on-machine measurements were within $0.12^{\circ}$ for different bending angles ranging from $30^{\circ}$ to $90^{\circ}$, the on-machine measurement based on 
Fig. 13 Laser beam tracking, a original image; $\mathbf{b}$ tracking image a
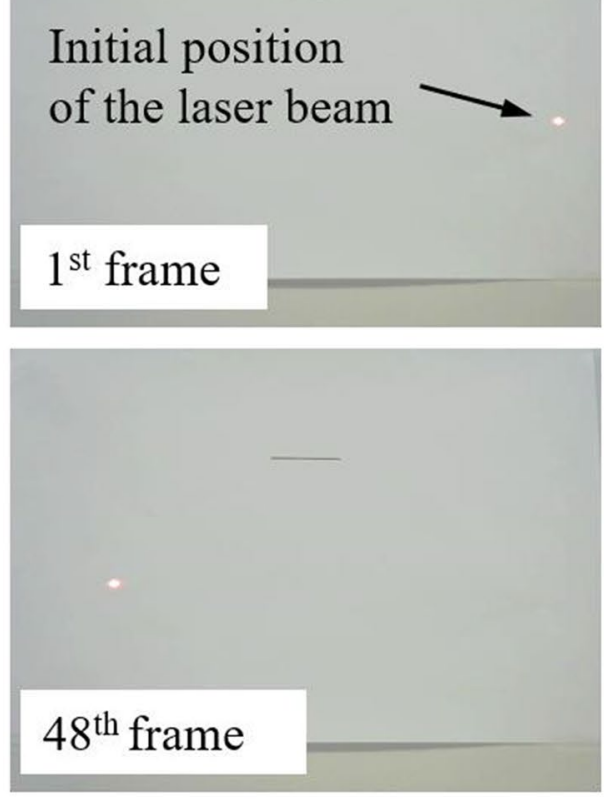

b
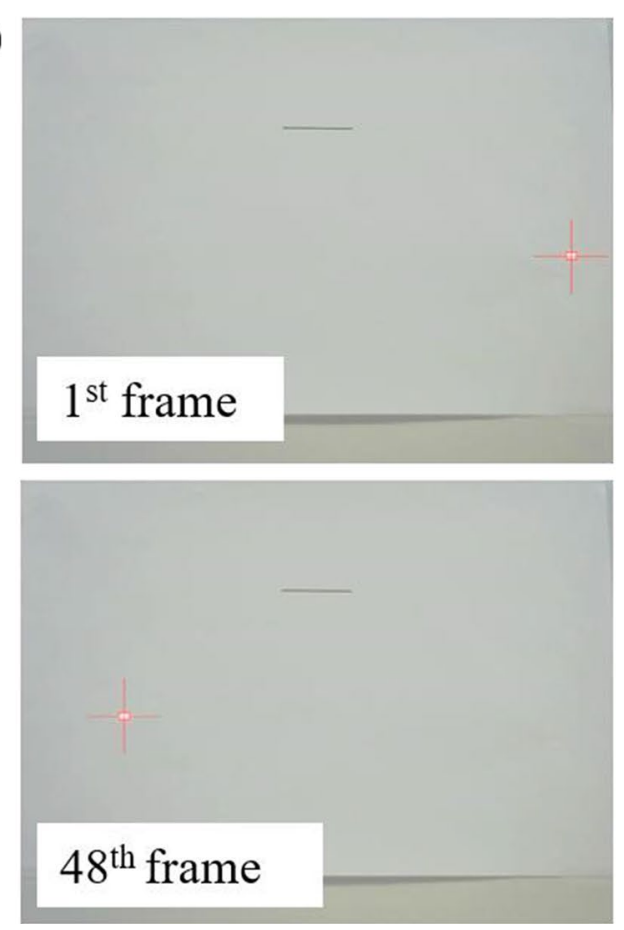

\section{$45^{\text {th }}$ frame}
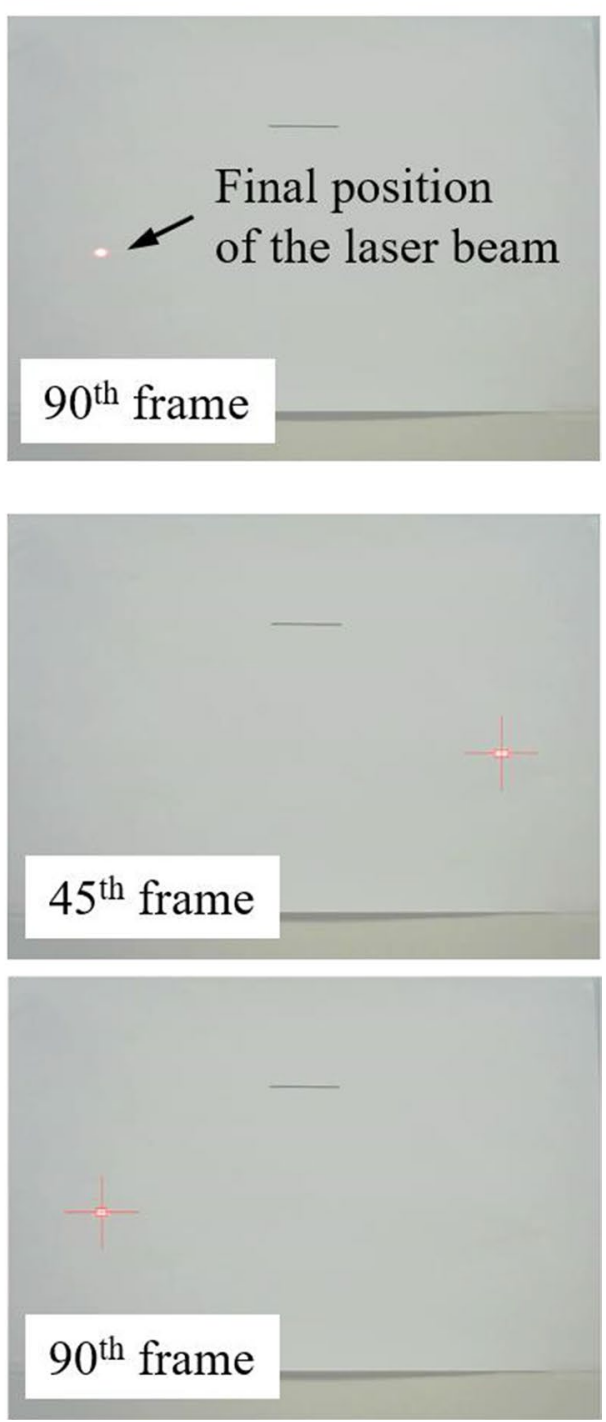

image processing captured the springback trend well. The on-machine springback measurement data in Fig. 14 and Fig. 15 show that there is no appreciable difference comparing the two methods through four different bend angles with three samples for each angle. With these validation results, the on-machine measurement by image processing appears to be a feasible springback measurement strategy for profile bending.

\section{Conclusion}

In this paper, a cost-effective system for on-machine springback measurement in RDB has been developed using digital image processing and laser tracking. The system was integrated with a 635-nm laser, an affordable image acquisition device, and an image processing technology. Springback was evaluated in real time, while eliminating the need 
Table 1 Springback measurement results (unit: degree)

\begin{tabular}{llllll}
\hline Measurement & Workpiece & \multicolumn{5}{l}{ Bending angle } \\
\cline { 3 - 6 } & & $30^{\circ}$ & $45^{\circ}$ & $60^{\circ}$ & $90^{\circ}$ \\
\hline Manual & 1 & 2.99 & 3.68 & 4.31 & 5.51 \\
& 2 & 3.05 & 3.80 & 4.27 & 5.77 \\
& 3 & 3.31 & 3.77 & 4.44 & 5.57 \\
& Average (1) & 3.12 & 3.75 & 4.34 & 5.62 \\
On-machine & Stand. Dev & 0.17 & 0.06 & 0.09 & 0.14 \\
& 1 & 3.11 & 3.80 & 4.19 & 5.62 \\
& 2 & 3.25 & 3.93 & 4.37 & 5.69 \\
& 3 & 3.37 & 3.85 & 4.36 & 5.74 \\
Difference |(1)_(2) & Average (2) & 3.24 & 3.86 & 4.31 & 5.68 \\
& Stand. Dev & 0.13 & 0.07 & 0.10 & 0.06 \\
& & 0.12 & 0.11 & 0.03 & 0.06 \\
\hline
\end{tabular}

for transferring the workpiece to an off-line measurement device.

The newly developed measurement method was applied to AA6082-T4 rectangular tube bending at $30^{\circ}, 45^{\circ}, 60^{\circ}$, and $90^{\circ}$. A target board to display a laser beam was set at $3.0 \mathrm{~m}$ from the center of a bend die. Every color image acquired by a webcam was quantized to a gray scale with the intensity value ranging from 0 to 255 . Then, the gray scale was binarized by thresholding based on the image histogram to extract the laser beam from the image background. The springback angle was calculated by updating the beam location of the images. The performance of the on-machine measurement method was validated by comparing it to conventional manual measurements. The average SD of the on-machine measurement was $0.09^{\circ}$ ranging from $0.06^{\circ}$ to $0.13^{\circ}$ while the corresponding value for manual measurement was about $0.12^{\circ}$. The differences between the averaged manual and on-machine measurements were within $0.12^{\circ}$ ranging from $0.03^{\circ}$ to $0.12^{\circ}$, and the on-machine measurement was found to be in a good agreement with the manual measurement. The affordable hardware system and tracking algorithm based on MATLAB were sufficient to capture the physical springback angle compared to the manually measured data.

The measurement strategy with the integration of a laser and an image processing technology enables a bending process to be monitored in real time and the springback angles to be measured on a tube bending machine. Thus, the present approach provides an attractive measurement technique that can be adopted to improve manufacturing efficiency. For implementation, the laser and camera
Fig. 14 Springback comparison based on each workpiece

\section{Manual measurement On-machine measurement}

a
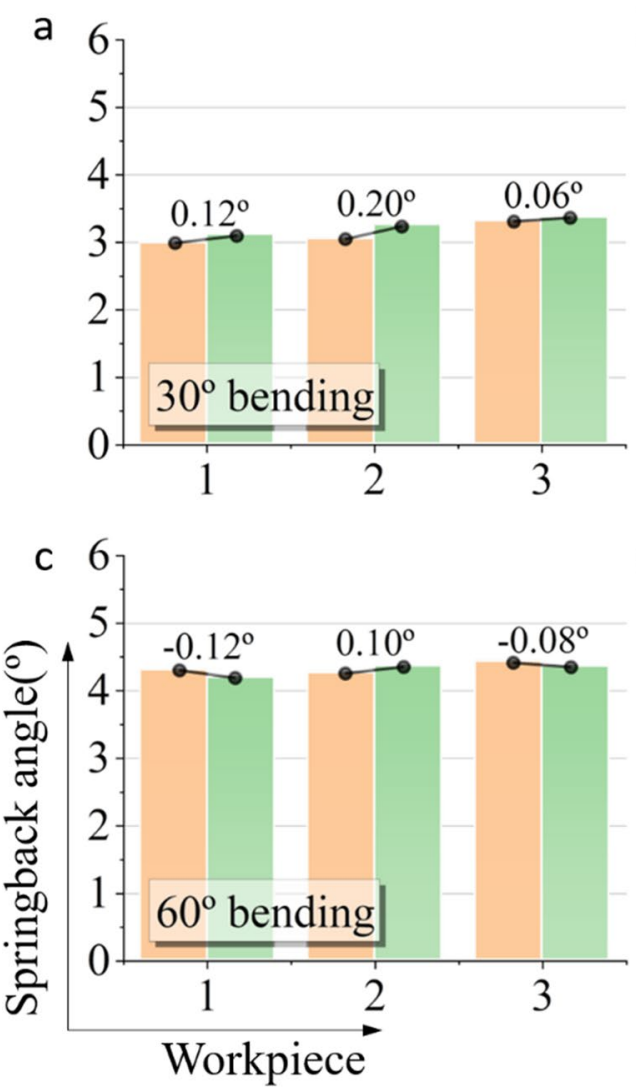

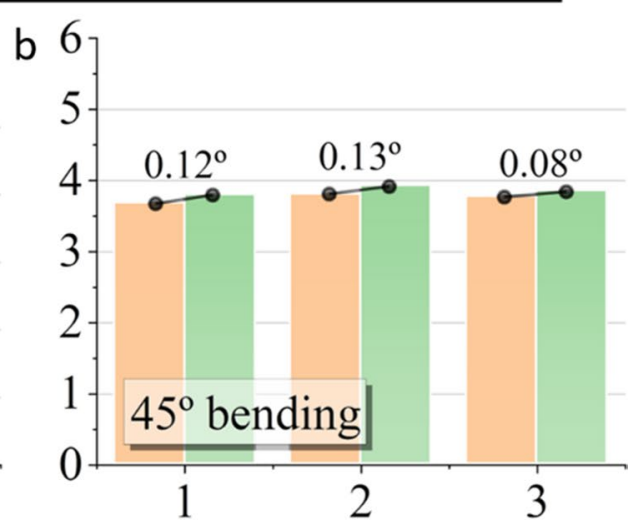

d 6

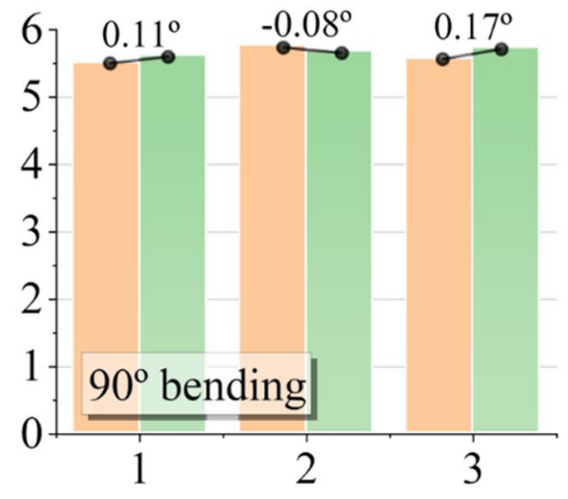


(a)

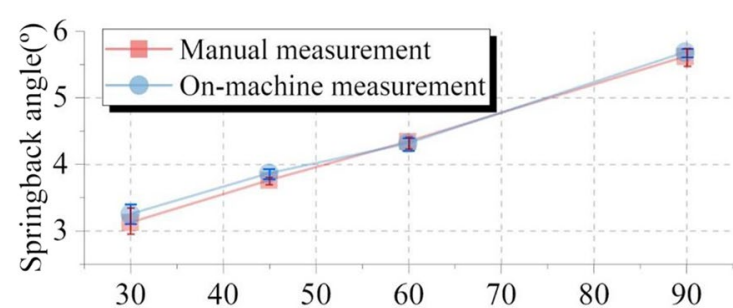

(b)

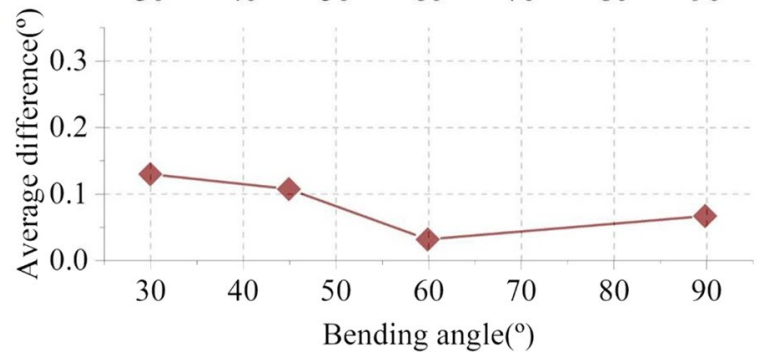

Fig. 15 a Average springback angle; b difference between the averaged manual and on-machine measurements

hardware are easily available. With hardware connection, the laser beam detection, object tracking, and springback calculation programs can be executed in a computer to collect springback data for progress control in a smart manufacturing environment. The digital images and the extracted springback data can be store in a cloud data platform and become an essential component of a data-driven decision system where product quality is predicated. The on-machine measurement and real-time process monitoring technology can facilitate manufacturing digital transformation towards Industry 4.0.

Author contribution T.H.: developed original concept, performed experiment, conducted data analysis, wrote the manuscript; T.W. and G.R.: secured funding, reviewed concept, supervised experiments; J.W.: reviewed concept, supervised data analysis, edited manuscript.

Funding Open access funding provided by NTNU Norwegian University of Science and Technology (incl St. Olavs Hospital - Trondheim University Hospital). This work was financially supported by the Norwegian University of Science and Technology (NTNU), NTNU Aluminium Product Innovation Center (NAPIC), and the Value project No. 267768 of the Research Council of Norway.

Data availability Data availability is under the NAPIC guideline.

Code availability Code availability is under the NAPIC guideline.

\section{Declarations}

Ethics approval Not applicable.

Consent to participate Not applicable.
Consent for publication No consent is required.

Competing interests The authors declare no competing interests.

Open Access This article is licensed under a Creative Commons Attribution 4.0 International License, which permits use, sharing, adaptation, distribution and reproduction in any medium or format, as long as you give appropriate credit to the original author(s) and the source, provide a link to the Creative Commons licence, and indicate if changes were made. The images or other third party material in this article are included in the article's Creative Commons licence, unless indicated otherwise in a credit line to the material. If material is not included in the article's Creative Commons licence and your intended use is not permitted by statutory regulation or exceeds the permitted use, you will need to obtain permission directly from the copyright holder. To view a copy of this licence, visit http://creativecommons.org/licenses/by/4.0/.

\section{References}

1. Allwood JM, Duncan SR, Cao J et al (2016) Closed-loop control of product properties in metal forming. CIRP Ann 65:573-596. https://doi.org/10.1016/j.cirp.2016.06.002

2. Welo T, Granly B (2010) A new adaptive bending method using closed loop feedback control. Trans Nonferrous Metals Soc China 20:2111-2117. https://doi.org/10.1016/S1003-6326(09) 60426-X

3. Löbbe C, Hoppe C, Becker C, Tekkaya AE (2015) Closed loop springback control in progressive die bending by induction heating. Int J Precis Eng Manuf 16:2441-2449. https://doi.org/10. 1007/s12541-015-0314-8

4. Pan K, Stelson KA (1995) On the plastic deformation of a tube during bending. J Eng Ind 117:494-500. https://doi.org/10. 1115/1.2803526

5. Borchmann L, Kuhnhen C, Frohn P, Engel B (2019) Sensitivity analysis of the rotary draw bending process as a database of digital equipping support. Procedia Manuf 29:592-599. https:// doi.org/10.1016/j.promfg.2019.02.100

6. Garcia-Romeu ML, Ciurana J, Ferrer I (2007) Springback determination of sheet metals in an air bending process based on an experimental work. J Mater Process Technol 191:174-177. https://doi.org/10.1016/j.jmatprotec.2007.03.019

7. Wang J, Verma S, Alexander R, Gau J-T (2008) Springback control of sheet metal air bending process. J Manuf Process 10:21-27. https://doi.org/10.1016/j.manpro.2007.09.001

8. Inamdar MV, Date PP, Desai UB (2000) Studies on the prediction of springback in air vee bending of metallic sheets using an artificial neural network. J Mater Process Technol 108:45-54. https://doi.org/10.1016/S0924-0136(00)00588-4

9. Ghiotti A, Simonetto E, Bruschi S, Bariani PF (2017) Springback measurement in three roll push bending process of hollow structural sections. CIRP Ann 66:289-292. https://doi.org/10. 1016/j.cirp.2017.04.119

10. Wang H, Zhou J, Zhao T, Tao Y (2016) Springback compensation of automotive panel based on three-dimensional scanning and reverse engineering. Int J Adv Manuf Technol 85:11871193. https://doi.org/10.1007/s00170-015-8042-x

11. Katona S, Lušić M, Koch M, Wartzack S (2016) Integrating optical 3D measurement techniques in pipe bending: a modelbased approach minimizing waste by deriving real functional design behaviour. Procedia CIRP 50:808-812. https://doi.org/ 10.1016/j.procir.2016.04.163 
12. Lau K, Hocken R, Haynes L (1985) Robot performance measurements using automatic laser tracking techniques. Robot Comput Integr Manuf 2:227-236. https://doi.org/10.1016/07365845(85)90110-3

13. Ha T, Ma J, Blindheim J et al (2020) In-line springback measurement for tube bending using a laser system. Procedia Manuf 47:766-773. https://doi.org/10.1016/j.promfg.2020.04.233

14. Solomon C, Breckon T (2011) Fundamentals of digital image processing: a practical approach with examples in Matlab. Wiley

15. Ferreira JA, Sun P, Grácio JJ (2006) Close loop control of a hydraulic press for springback analysis. J Mater Process Technol 177:377-381. https://doi.org/10.1016/j.jmatprotec.2006.03.177

16. Pratt WK (2007) Digital image processing. Wiley-Interscience, New York

17. Sahoo PK, Soltani S, Wong AK (1988) A survey of thresholding techniques. Comput Vis Graph Image Process 41:233-260. https://doi.org/10.1016/0734-189X(88)90022-9
18. Piccardi M (2004) Background subtraction techniques: a review. In: 2004 IEEE International Conference on Systems, Man and Cybernetics (IEEE Cat. No.04CH37583). pp 3099-3104. https://doi.org/10.1109/icsmc.2004.1400815

19. Sen-Ching SC, Kamath C (2004) Robust techniques for background subtraction in urban traffic video. In: Visual Communications and Image Processing 2004. International Society for Optics and Photonics, pp 881-892. https://doi.org/10.1117/12.526886

20. Pal NR, Pal SK (1993) A review on image segmentation techniques. Pattern Recogn 26:1277-1294. https://doi.org/10.1016/ 0031-3203(93)90135-J

21. Yilmaz A, Javed O, Shah M (2006) Object tracking: a survey. Acm computing surveys (CSUR) 38:13-es. https://doi.org/10. $1145 / 1177352.1177355$

Publisher's note Springer Nature remains neutral with regard to jurisdictional claims in published maps and institutional affiliations. 